\title{
PREPARATION AND CHARACTERIZATION OF NANOFIBRILLATED CELLULOSE/POLY (VINYL ALCOHOL) COMPOSITE FILMS
}

\author{
Behzad Kord ${ }^{1, \star}$, Behrouz Malekian $^{2}$, Hossein Yousefi ${ }^{3}$, Abdollah Najaf $^{4}$
}

\begin{abstract}
Poly (vinyl alcohol) based composite films with different loadings of cellulose nanofibrils were prepared using a solvent casting method and their tensile, optical and wettability properties were tested. The morphology of both neat poly (vinyl alcohol) and nanocomposites was explored by using a field emission scanning electron microscope technique. Results indicated that the tensile strength and Young's modulus of poly (vinyl alcohol) composite films were significantly improved with the increase of cellulose nanofibrils loading. However, the percentage of elongation at break decreased with increasing of cellulose nanofibrils. The films became increasingly opaque with increasing cellulose nanofibrils contents, although the composites also retained moderate transparency. The samples containing cellulose nanofibrils exhibited higher hydrophobicity compared with that of neat poly (vinyl alcohol). Field emission scanning electron microscope micrographs revealed that the cellulose nanofibrils were homogeneously dispersed in the poly (vinyl alcohol) matrix.
\end{abstract}

Keywords: Cellulose nanofibril, color measurement, contact angle, tensile properties, transparency.

\section{INTRODUCTION}

In recent years, biodegradable polymers obtained from renewable resources have attracted much attention due to the increasing environmental awareness and the fossil depletion problem (Vroman and Tighzert 2009). This recent evolution incites researchers and industrials to develop novel materials labeled as "environment-friendly," derivates from alternative resources, with low energy consumption, biodegradable, and nontoxic for the environment (Lendlein and Sisson 2011). Biopolymers research and development as well as their applications have been the fastest for several years. The most popular biodegradable polymers are poly (vinyl alcohol) (PVA), poly (lactic acid) (PLA), poly-caprolactone (PCL), poly (butylene adipate terephthalate) (PBAT) and polyhydroxybutyrate (PHB) (Lendlein and Sisson 2011). Among the renewable source-based biodegradable plastics, poly (vinyl alcohol) (PVA) is one of the most promising materials since it is thermoplastic, biodegradable, biocompatible and has high-strength, high-modulus and good processability (Lu et al. 2008, Roohani et al. 2008). It

${ }^{1}$ Assistant professor, Department of Paper and Packaging Technology, Faculty of Chemistry and Petrochemical Engineering, Standard Research Institute (SRI), Karaj, Iran.

${ }^{2}$ Member of Young Researchers and Elite Club, Chalous Branch, Islamic Azad University, Chalous, Iran.

${ }^{3}$ Assistant Professor, Department of Wood Engineering and Technology, Gorgan University of Agriculture Sciences and Natural Resources, Gorgan, Iran.

${ }^{4}$ Associate Professor, Department of Wood and Paper Science and Technology, Chalous Branch, Islamic Azad University,

Chalous, Iran.

•Corresponding author: b.kord@standard.ac.ir

Received: 03.04.2016 Accepted: 31.08.2016 
is water soluble, semi-crystalline with the excellent chemical resistance, and has no toxic action on the human body (Qua et al. 2009, Kaboorani et al. 2012). PVA is widely used in adhesives, paints, sealants, coatings, textiles, plastics, tissue scaffolding, filtration materials, membranes, optics, enzyme immobilization, drug release, etc (Roohani et al. 2008, Qua et al. 2009, Kaboorani et al. 2012).

However, brittleness and other properties such as low thermal stability, high flammability, medium gas barrier properties and low solvent resistance (e.g., against water) of the pure PVA are often insufficient for its applications (Qua et al. 2009, Kaboorani et al. 2012, Cheng et al. 2009). Many attempts have been made to overcome the drawbacks. Recent research has shown that these drawbacks may be particularly overcome by the incorporation of nano-sized particles into the polymer matrix (Roohani et al. 2008, Qua et al. 2009, Kaboorani et al. 2012, Cheng et al. 2009, Li et al. 2014, Qiu and Netravali 2012, Peresin et al. 2010). Currently, numerous efforts in the academic and industrial fields are focused on the use of nanocellulose reinforcements in the polymer matrix (Favier et al. 1995, Azizi Samir et al. 2004, Ganster and Fink 2006, Henriksson et al. 2007, Hubbe et al. 2008, Iwatake et al. 2008, Eichhorn et al. 2010, Abdul Khalil et al. 2012, Frone et al. 2013). Nanocellulose which typically have a width of 5 to $50 \mathrm{~nm}$ and a high specific surface area, have seen rapid advancement and considerable interest in the last decade (Ganster and Fink 2006, Henriksson et al. 2007, Hubbe et al. 2008). It is predicted that nanocellulose reinforcements in the polymer matrix may provide the value-added materials with superior performance and extensive applications for the next generation (Eichhorn et $a l$. 2010, Abdul Khalil et al. 2012, Frone et al. 2013). Among different kinds of nanocellulose materials, cellulose nanofibrils (NFC) are ideal candidates for reinforced composites owing to their abundance, renewability, biodegradability, spectacular mechanical properties (high specific strength and modulus), low thermal expansion, environmental benefiits, and low cost (Hubbe et al. 2008, Iwatake et al. 2008, Eichhorn et al. 2010, Abdul Khalil et al. 2012, Frone et al. 2013). Cellulose nanofibrils (NFC) have been gaining considerable interest as reinforcement as they are more effective than their microsized counterparts in reinforcing polymers as they form a percolated network connected by hydrogen bonds, provided there is a good dispersion of the nanofibers in the matrix (Eichhorn et al. 2010).

In this work, nanofibrils (NFC) isolated by mechanical treatment of commercial pulp were used to prepare composites with poly (vinyl alcohol) by solvent casting. The aim of the present investigation was to study the influence of the concentration of cellulose nanofibrils on the morphological, mechanical, optical, and wettability of PVA films.

\section{EXPERIMENTAL}

\section{Materials}

Polyvinyl alcohol (PVA) (average molecular weight: $72000 \mathrm{~g} / \mathrm{mol}$; polymerization degree: 1600; hydrolysis degree: 97.5 - $99.5 \mathrm{~mol} \%$ ), was purchased from Sigma-Aldrich. Bleached softwood Kraft pulp was supplied from SCA's pulp mill in Östrand, Sweden.

\section{Preparation of nanofibrillated cellulose}

Cellulose nanofibrils were obtained through mechanical fibrillation of bleached softwood Kraft pulp. The pulp was dispersed homogeneously in distilled water using a laboratory shear mixer, and then a slurry with a cellulose concentration about $1 \mathrm{wt} \%$ was passed once through a disk grinder (MKCA62, Masuko Sangyo Co, Japan). The fibrillation was done using contact mode grinding, where the final gap distance between the grinding stones (from 0-point) was further decreased by $10 \mu \mathrm{m}$ during the grinding. The grinding speed was approximately $1500 \mathrm{rpm}$ and the total processing time was around $30 \mathrm{~min}$. The resulting suspension was filtered by vacuuming to achieve 3\% nanofiberils content in solution. 


\section{Manufacture of composite films}

PVA and NFC-reinforced PVA composite films were prepared using a solvent casting method. Five grams of PVA were dissolved in $100 \mathrm{~mL}$ of distilled water at $90{ }^{\circ} \mathrm{C}$ for 60 min under mechanical stirring. Then, the solutions were kept under stirring to reach room temperature. The dissolved solution was cast on Teflon glass plate and slowly dried at room temperature for $24 \mathrm{~h}$. The resultant film was peeled from the casting surface. To obtain nanocomposite films, the NFC solutions were mixed with the previously prepared PLA solution, sonicated for $30 \mathrm{~min}$ at room temperature using an Ultrasonic Processor (model Zinsser Analytic Gmbh, Germany). The resulting mixture was cast in a Teflon mold and placed in a $35^{\circ} \mathrm{C}$ oven to evaporate water. Composite films with different NFC loadings $(5,10,15$ and $20 \mathrm{wt} \%$ ) were prepared. The obtained films were conditioned at $23 \pm 2{ }^{\circ} \mathrm{C}$ and $50 \pm 5 \%$ relative humidity for at least $48 \mathrm{~h}$ prior to testing.

\section{Characterization}

\section{Film thickness}

The thickness of the composite films was measured using a digital micrometer (model ID-F 125E, Mitutoyo, Japan) at an accuracy of 0,001 $\mathrm{mm}$.

\section{Morphological study}

Studies on the morphology of the composite films were carried out using a field emission scanning electron microscope (FE-SEM). FE-SEM micrographs of the surfaces of specimen were taken using FE-SEM model TESCAN MIRA 3 XMU. The fracture surface of specimen was coated with a thin film of platinum/palladium to avoid electrical charge accumulation during the examination and then analyzed at an acceleration voltage of $5 \mathrm{kV}$.

\section{Tensile tests}

The tensile tests were performed using a universal testing machine (Model 4465, Instron Corporation, MA, USA). Tensile strength, tensile modulus and elongation at break of each film were measured from the tests conducted according to ASTM D 882. Initial grip separation was set at $50 \mathrm{~mm}$ and cross-head speed at $5 \mathrm{~mm} / \mathrm{min}$. At least five test samples were tested for each material and the average values are presented.

\section{Color measurement}

Color measurement of specimen was measured using a spectrophotometer (Sheen, USA) under a D65 light source with a test window diameter of $8 \mathrm{~mm}$. Based on the CIE L*a*b* color system, $\mathrm{L} *$ is the value on the white/black axis, $a^{*}$ is the value on the red/green axis, $b^{*}$ is the value on the yellow/ blue axis. Then, the total color change (DE) of samples was calculated from Equ. 1:

$$
\Delta E=\sqrt{\Delta l^{2}+\Delta a^{2}+\Delta b^{2}}
$$

Where $\mathrm{Dl}, \mathrm{Da}$, and $\mathrm{Db}$ represent the difference between the initial and final values of $\mathrm{L}^{*}, \mathrm{a}^{*}$, and $\mathrm{b}^{*}$, respectively. The surface color for three replicates was measured at five locations on each formulation.

\section{Transmittance analysis}

Film transparency was determined by measuring the percent transmittance at $800 \mathrm{~nm}$ using a UV/ VIS spectrophotometer (Model 8451A, Hewlett-Packard Co, Santa Clara, CA, USA).

\section{Contact angle measurement}

The static contact angle of film samples were measured according to the sessile-drop method using a contact angle analyzer (model PG-X Goniometer, Thwing-Albert Instrument Co, Switzerland). Distilled water of approximately $2,5 \mathrm{ml}$ was dropped onto the surface of the films and depletion of the droplets was immediately recorded by a digital video camera. Image capturing continued from the 
beginning of the test until when the droplets disappeared from the surface of the samples. The image analysis system was used to calculate the left and right angles from the shape of the drop with an accuracy of $\pm 0,1^{\circ}$. All data presented were the mean values of five independent measurements.

\section{RESULTS AND DISCUSSION}

\section{Thickness of composite films}

Effects of cellulose nanofibrils loading on thickness of neat PVA and PVA/NFC nanocomposite films are shown in Figure 1. As can be seen, the thickness of the PVA/NFC nanocomposite films increased significantly compared to the control PVA film, which is due to the increase in solid content.

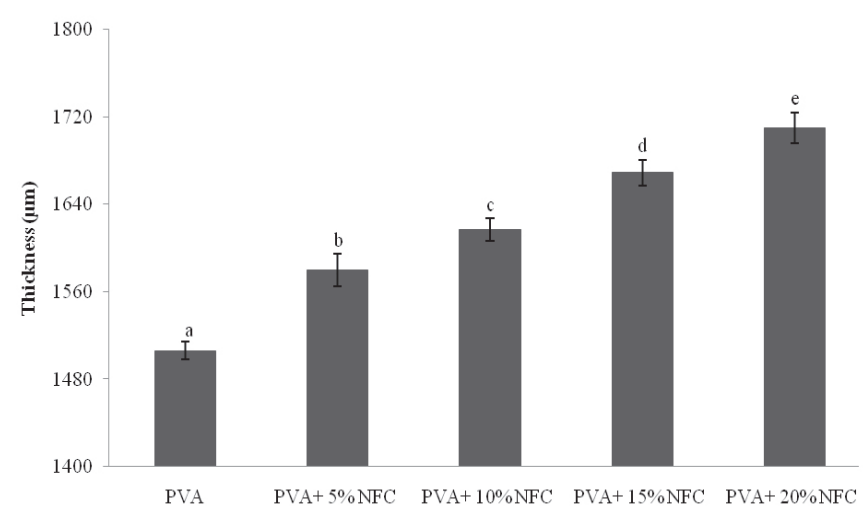

Figure 1. Thickness of neat PVA and various types of PVA/NFC nanocomposite films.

\section{Morphology of composite films}

Microphotographs of PVA and NFC-reinforced PVA composite films are shown in Figure 2. No voids signifying cellulose nanofibrils pull-outs were observed for composites with NFC content up to $20 \%$. The images show that fracture surface was relatively rougher for the nanocomposites, compared to the neat PVA films. Generally, the images show that the cellulose nanofibrils were homogeneously dispersed in the PVA matrix. The white dots, having different sizes, on the nanocomposites, can be considered as NFC. The amount of these smaller white dots was found to increase with increasing NFC content, indicating that theses smaller white dots were mostly indications of NFC dispersed in PVA matrix. Furthermore, the processing route used, which involved solution-casting followed by sonication, can be considered as an efficient method to distribute cellulose nanofibrils reinforcements in PVA matrix. 

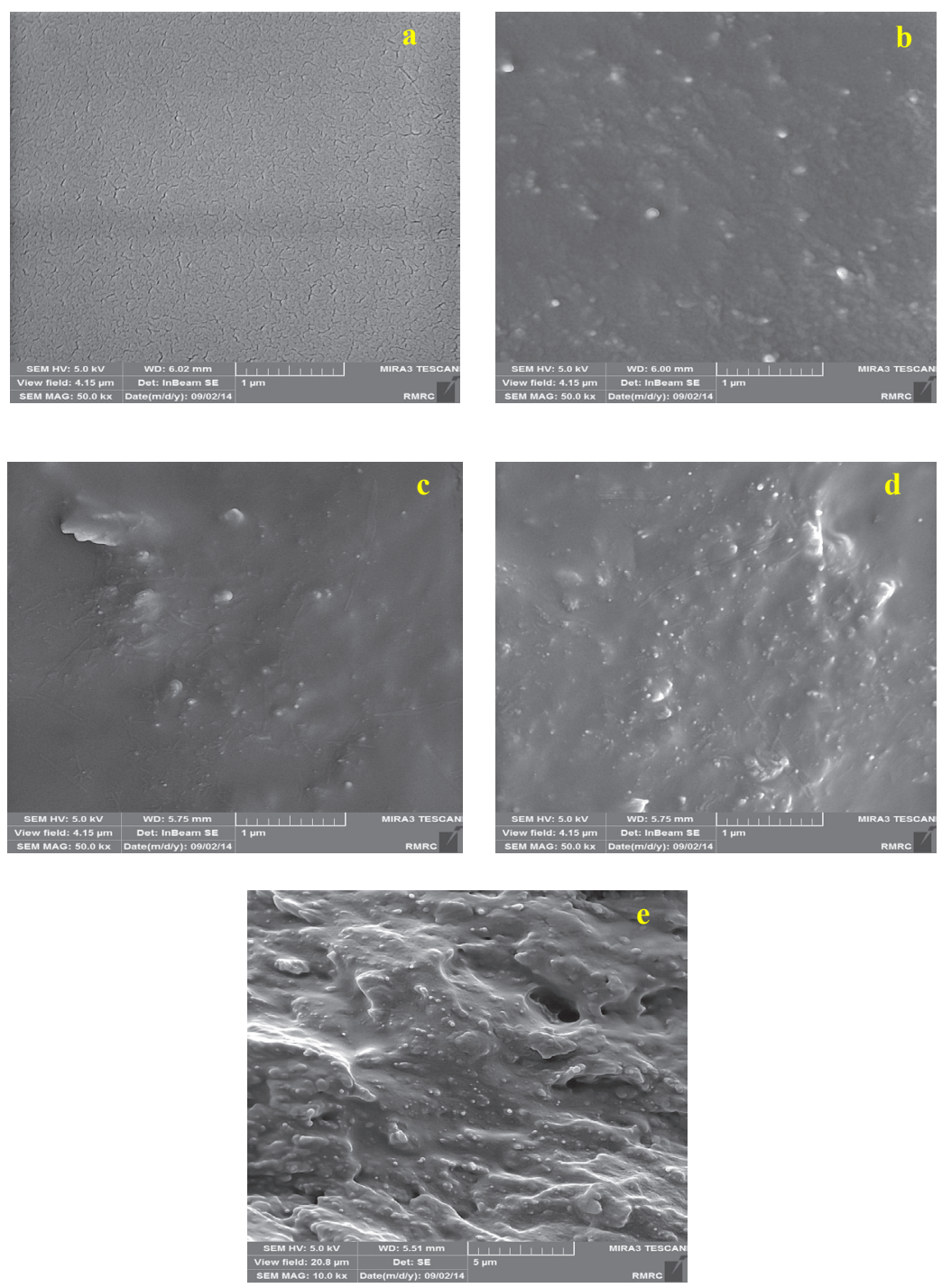

Figure 2. FE-SEM micrographs of fracture surface of composite films a) neat PVA b) PVA $+5 \%$ NFC c) PVA $+10 \%$ NFC d) PVA $+15 \%$ NFC e) PVA $+20 \%$ NFC.

\section{Tensile properties of composite films}

Figure 3 shows the results of tensile strength test on neat PVA and PVA/NFC nanocomposites with $5,10,15$ and $20 \mathrm{wt} \%$ NFC. The tensile strength of neat PVA film was $18,13 \mathrm{MPa}$. As the loading of NFC increased from 5, 10, 15 and $20 \mathrm{wt} \%$ (based on PVA weight), tensile strength of PVA composite films increased to 29,$8 ; 58,08 ; 91,9$ and $133,4 \%$ respectively. The intermolecular forces between NFC and the base PVA matrix may enhance the tensile strength of the PVA composite films. The intermolecular forces keep the inherent tensile strength of the fibrils intact and results in enhancement of the tensile strength of the films (Lu et al. 2008, Li et al. 2014). It is worth nothing that the mutual affinity of the PVA matrix and NFC with hydroxyl-rich surfaces, leads to the strong interactions between them (Roohani et al. 2008). The resulting hydrogen bonds should strengthen the interface significantly with a positive impact on the mechanical properties of the composite material (Qua et al. 2009, Kaboorani et al. 2012). In other hand, these interactions can partially hinder the formation of the expected percolating cellulosic network (Azizi Samir et al. 2004, Hubbe et al. 2008, Eichhorn et al. 
2010). However, some reports have attributed the strong reinforcing effect of the NFC to the formation of a networked structure above percolation threshold resulting from hydrogen bonding (Sakurada et al. 1962, Hajji et al. 1996, Lu et al. 2008, Kaboorani et al. 2012, Li et al. 2014). Furthermore, the improvement in tensile strength for PVA/NFC nanocomposites compared to neat PVA was mainly attributable to the high mechanical properties of NFC on compared to that of the matrix (Lee et al. 2009, Peresin et al. 2010).

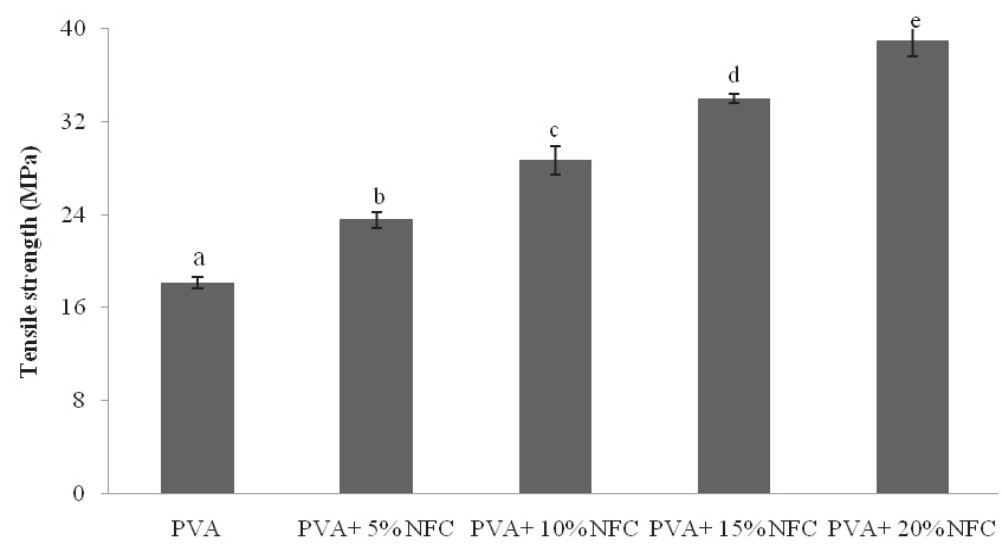

Figure 3. Tensile strength of neat PVA and various types of PVA/NFC nanocomposite films.

The tensile modulus of NFC reinforced PVA films were represented in Figure 4. The tensile modulus increased with the increasing of NFC loading from 5 to $20 \mathrm{wt} \%$. When the NFC content was $20 \mathrm{wt} \%$, the tensile modulus of the PVA composites reached maximum values, which were 1,7 times larger than that of neat PVA, respectively. PVA films prepared by the loading levels $(5,10,15$ and 20 $\mathrm{wt} \%$ ) of NFC showed 11,$4 ; 25,3 ; 50,5$ and $57,2 \%$ higher tensile modulus than those made with neat PVA. The increased tensile modulus may be related to the increased stiffness and brittleness of hybrid composite films by the addition of NFC (Lee et al. 2009, Visakh et al. 2012, Li et al. 2014).

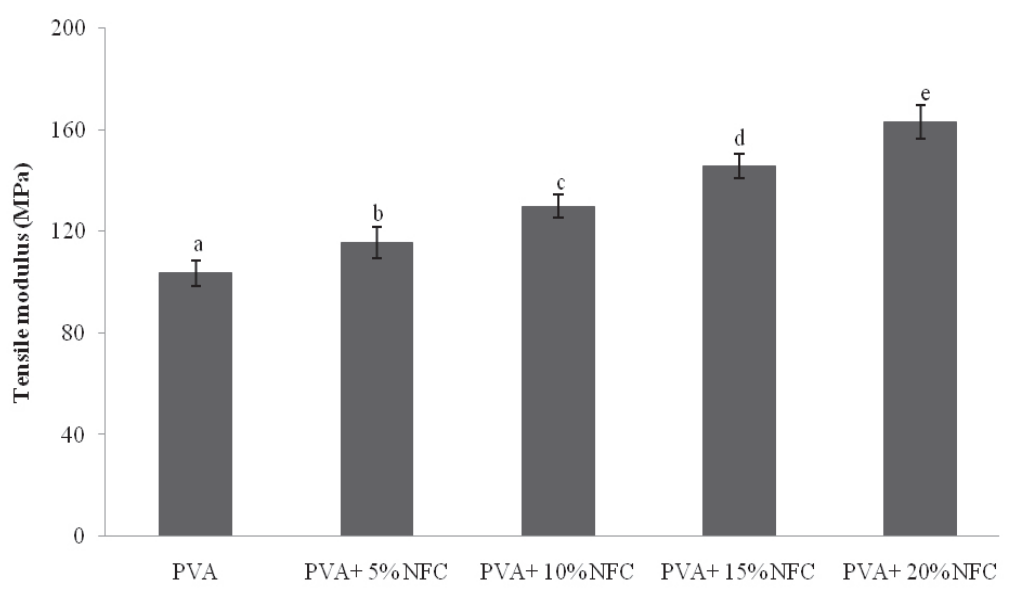

Figure 4. Tensile modulus of neat PVA and various types of PVA/NFC nanocomposite films.

Figure 5 shows the effects of cellulose nanofibrils on the elongation at break of PVA composite films. As can be seen, the percentage of elongation at break decreased with increasing of cellulose nanofibrils concentration. PVA showed an elongation at break of $211 \%$, whereas the nanocomposites with 5,10 , 
15 and $20 \mathrm{wt} \%$ NFC showed an elongation at break of $176 \%, 148 \%, 123 \%$ and $109 \%$ respectively. This is because the rigidity of matrix increased by adding the NFC (Visakh et al. 2012). Moreover, strong interaction between cellulose nanofibrils and PVA chains could restrict chain movements and consequently blocks its ability to flow and reduce its ductility (Qua et al. 2009, Visakh et al. 2012).

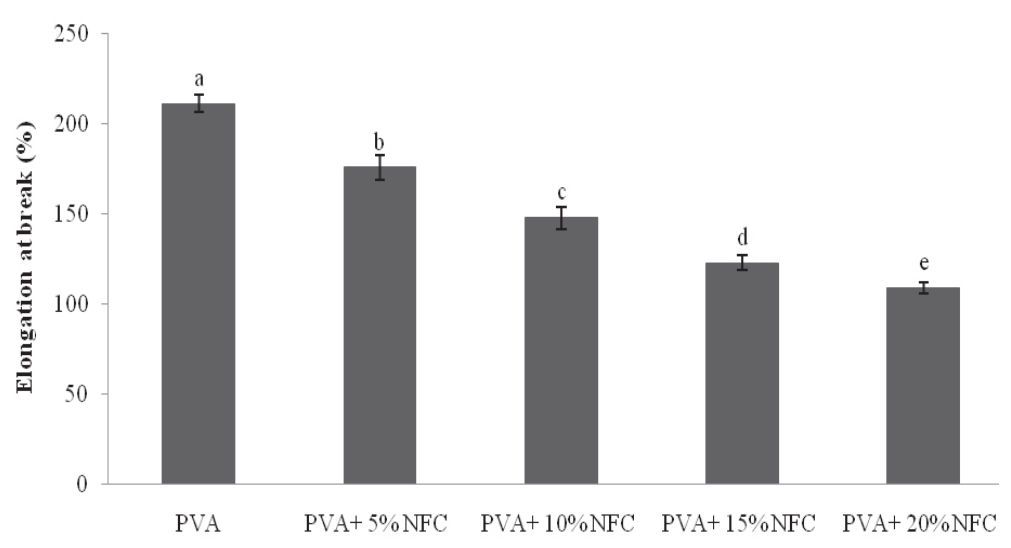

Figure 5. Elongation at break of neat PVA and various types of PVA/NFC nanocomposite films.

\section{Color changes of composite films}

Color evaluation is an important quality parameter for potential industrial applications of films, because consumers often associate aspects such as brightness and color of products which can be affected by the coatings and films with product quality (Andrade-Pizarro et al. 2010). The values of change for all three color parameters $\left(\mathrm{L}^{*}, \mathrm{a}^{*}\right.$ and $\left.\mathrm{b}^{*}\right)$ as well as the total color changes $(\Delta \mathrm{E})$ are presents in Table 1. As can be seen, the rates of changes of the color parameters, and consequently the total color changes of PVA composite films significantly increased by adding the NFC. This increase is due to the greater amount of solids contained in the film, which in turn increases the concentration of NFC (Rhim et al. 2009, Andrade-Pizarro et al. 2010).

Table 1. Color parameters of PVA and PVA/NFC nanocomposite films.

\begin{tabular}{|l|l|l|l|l|l|l|l|}
\hline Specimens & $\mathrm{L}^{*}$ & $\mathrm{a}^{*}$ & $\mathrm{~b}^{*}$ & $\Delta \mathrm{L}$ & $\Delta \mathrm{a}$ & $\Delta \mathrm{b}$ & $\Delta \mathrm{E}$ \\
\hline PVA & 64,38 & $-3,31$ & 0,73 & - & - & - & - \\
\hline PVA+ 5\% NFC & 72,64 & $-4,05$ & 1,74 & 8,26 & 7,36 & 1,01 & 11,10 \\
\hline PVA+ 10\% NFC & 77,52 & $-1,99$ & 1,90 & 13,14 & 5,3 & 1,17 & 14,21 \\
\hline PVA+ 15\% NFC & 79,29 & $-3,71$ & 2,83 & 14,91 & 7,02 & 2,1 & 16,61 \\
\hline PVA+ 20\% NFC & 80,78 & $-2,18$ & 3,12 & 16,4 & 5,49 & 2,39 & 17,45 \\
\hline
\end{tabular}

\section{Transparency of composite films}

Film transparency provides information on the particle size of dispersed particle in PVA matrix. The particle sizes larger than the visible wavelength would obstruct light, leading to translucent or opaque films. However, transparency may be a $\square$ ected by various factors including film thickness (Kumar Thakur and Kumari Thakur 2015). The percent transmittance values of film samples are presented in Figure 6. From the figure, the neat PVA film due to the absence of light blockage particles exhibits the highest percent transmittance followed by the PVA/NFC nanocomposite films (Andrade-Pizarro et al. 2010). Another possible explanation for the decreased transparency of the composite films is due to the probable crystallization of solvent cast PVA films (Rhim et al. 2009). However, the large decrease in the transmittance of the composite films indirectly indicates that the NFC is not completely dispersed in 
the polymer matrix. In other hand, the transmittance of the neat PVA composite films was higher than the PVA/NFC nanocomposite films, possibly because the agglomerations of nanocellulose became a barrier to the penetration light (Li et al. 2014).

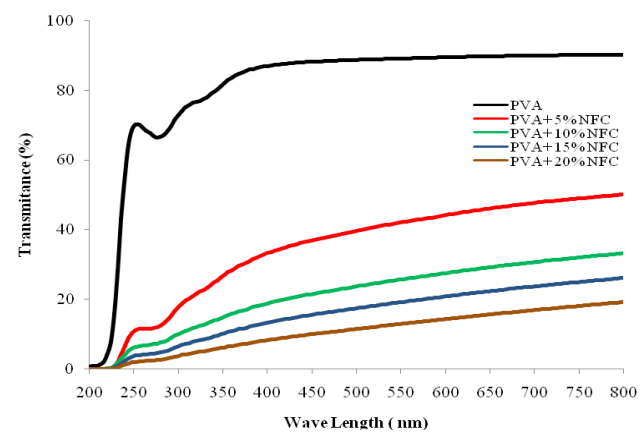

Figure 6. Transparency of neat PVA and various types of PVA/NFC nanocomposite films.

\section{Wettability of composite films}

Another interesting property of the composite film is the surface hydrophobicity, which was evaluated by means of contact angle determination. The contact angles of film samples are shown in Figure 7. It can be clearly seen that an increase in NFC content brought about a significant increase in contact angle values of the composite films. The contact angles of composite films increase from $73^{\circ}$ to $85^{\circ}, 82^{\circ}, 103^{\circ}$, and $111^{\circ}$ with an increase in the NFC content from 0 to $5,10,15$, and $20 \mathrm{wt} \%$, respectively. These results indicate that the hydrophobicity of PVA/NFC nanocomposite films is higher than the control PVA film. This phenomenon attributed to decreased surface energy, higher surface roughness as a result of NFC addition could contribute to increased hydrophobicity of PVA/NFC nanocomposite films (Lee et al. 2009). It can be expected that the addition of cellulose nanofibrils into the composite films improves their water resistance due to strengthened inter-component hydrogen bonding. The extensive hydrogen bonding between polymer matrix and NFC may disfavour the hydrogen bonding sites for water molecules (Kisonen et al. 2015).

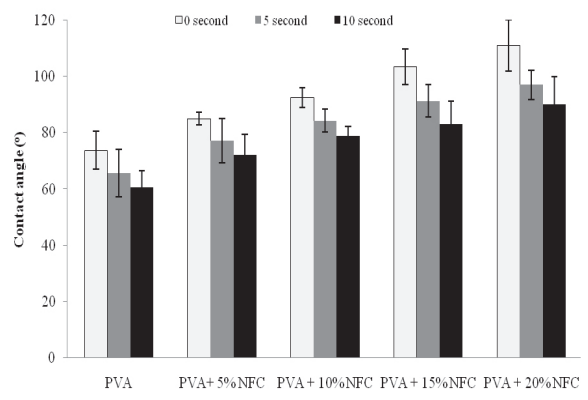

Figure 7. Contact angle of neat PVA and various types of PVA/NFC nanocomposite films.

\section{CONCLUSIONS}

The following conclusions could be drawn from the results of the present study:

The FE-SEM images indicated that NFC was uniformly distributed in the PVA matrix and the NFC-PVA bonding stronger efficiently by sonication process.

The tensile strength and modulus increased for the nanocomposites with the addition of NFC, accompanied by a great decrease in elongation at break. 
The films became increasingly opaque with increasing NFC contents, although the composites also retained moderate transparency.

The addition of NFC in the PVA matrix causes an increase of contact angle of $52 \%$, because the cellulose nanofibrils provide a more surface roughness path to water passing through the film.

\section{ACKNOWLEDGEMENTS}

Special thanks are due to the Nano Novin Polymer Co, for providing the facilities for prepares the cellulose nanofibrils. We also grateful Dr. Mehdi Roohani (Standard Research Institute), who gave us valuable knowledge of cellulosic nanomaterials.

\section{REFERENCES}

Abdul Khalil, H.P.S.; Bhat, A.H.; Ireana Yusra, AF. 2012. Green composites from sustainable cellulose nanofibrils: A review. Carbohyd Polym 87:963-979.

Andrade-Pizarro, R.D.; Skurtys, O.; Osorio-Lira, F. 2010. Effect of cellulose nanofibers concentration on mechanical, optical, and barrier properties of gelatin-based edible films. Dyna 191:219-226.

Azizi Samir, M.A.S. ; Alloin, F.; Sanchez, J.Y.; EI Kissi, N.; Dufresne A. 2004. Preparation of cellulose whiskers reinforced nanocomposites from an organic medium suspension. Macromolecules 37(4):1386-1393.

Cheng, Q.; Wang, S.; Rials, TG. 2009. Poly (vinyl alcohol) nanocomposites reinforced with cellulose fibrils isolated by high intensity ultrasonication. Composites Part A: Applied Science and Manufacturing 40(2): 218-224.

Eichhorn, S.J.; Dufresne, A.; Aranguren, M.; Marcovich, N.E.; Capadona J.R.; Rowan, S.J.; Weder, C.; Thielemans, W.; Roman, M.; Renneckar, S.; Gindl, W.; Veigel, S.; Keckes, J.; Yano, H.;Abe, K.; Nogi, M.; Nakagaito, A. N.; Mangalam, A.; Simonsen, J.; Benight, A. S.; Bismarck, A.; Berglund, L. A.; Peijs, T. 2010. Review: Current international research into cellulose nanofibres and nanocomposites. J Mater Sci 45(1):1-33.

Favier, F.; Chanzy, H.; Cavaille, J.Y. 1995. Polymer nanocomposites reinforced by cellulose whiskers. Macromolecules 28(18):6365-6367.

Frone, A.N.; Berlioz, S.; Chailan, J.F.; Panaitescu, D.M. 2013. Morphology and thermal properties of PLA-cellulose nanofibers composites. Carbohyd Polym 91: 377-384.

Ganster, J.; Fink, H.P. 2006. Novel cellulose fiber reinforced thermoplastic materials. Cellulose 13:271-280.

Hajji, P.; Cavaille, JY.; Favier, V.; Gauthier, C.; Vigier G. 1996. Tensile behavior of nanocomposites from latex and cellulose whiskers. Polym Compos 17(4):612-619.

Henriksson, M.; Henriksson, G.; Berglund, L.A.; Lindstrom, T. 2007. An environmentally friendly method for enzyme-assisted preparation of microfibrillated cellulose (MFC) nanofibers. Eur Polym J 43(8):3434-3441. 
Hubbe, M.A.; Rojas, O.J.; Lucia, L.A.; Sain, M. 2008. Cellulosic nanocomposites: A review. BioResources 3(3):929-980.

Iwatake, A.; Nogi, M.; Yano, H. 2008. Cellulose nanofiber-reinforced polylactic acid. Compos Sci Technol 68:2103-2106.

Kaboorani, A.; Riedl, B.; Blanchet, P.; Fellin, M.; Hosseinaei, O.; Wang, S. 2012. Nanocrystalline cellulose (NCC): A renewable nano-material for polyvinyl acetate (PVA) adhesive. Eur Polym J 48:1829-1837.

Kumar Thakur, V.; Kumari Thakur, M. 2015. Eco-friendly polymer nanocomposites: processing and properties. Springer, 579p.

Kisonen, V.; Prakobna, K.; Xu, C.; Salminen, A.; Mikkonen, K.S.; Valtakari, D.; Eklund, P.; Seppälä, J.; Tenkanen, M .; Willför, S. 2015. Composite films of nanofibrillated cellulose and O-acetyl galactoglucomannan (GGM) coated with succinic esters of GGM showing potential as barrier material in food packaging. J Mater Sci 50(8):3189-3199.

Lee, S.Y.; Mohan, D.J.; Kang, I.A.; Doh, G.H.; Lee, S.; Han, S.O. 2009. Nanocellulose reinforced PVA composite films: effects of acid treatment and filler loading. Fiber Polym 10(1):77-82.

Lendlein, A.; Sisson, A. 2011. Handbook of biodegradable polymers: isolation, synthesis, characterization and applications. John Wiley \& Sons, 405p.

Li, W.; Wu, Q.; Zhao, X.; Huang, Z.; Cao, J.; Li, J.; Liu, S. 2014. Enhanced thermal and mechanical properties of PVA composites formed with filamentous nanocellulose fibrils. Carbohyd Polym 113:403-410.

Lu, J.; Wang, T.; Drzal, L.T. 2008. Preparation and properties of microfibrillated cellulose polyvinyl alcohol composite materials. Appl Sci Manufact 39:738-746.

Peresin, M.S.; Habibi, Y.; Zoppe, J.O.; Pawlak, J.J.; Rojas, OJ. 2010. Nanofiber composites of polyvinyl alcohol and cellulose nanocrystals: manufacture and characterization. Biomacromolecules 11:674-681.

Qua, E.H.; Hornsby, P.R.; Sharma, H.S.; Lyons, G.; McCall, R.D. 2009. Preparation and Characterization of poly (vinyl alcohol) nanocomposites made from cellulose nanofibers. $J$ Appl Polym Sci 113:2238-2247.

Qiu, K.; Netravali, A.N. 2012. Fabrication and characterization of biodegradable composites based on microfibrillated cellulose and polyvinyl alcohol. Compos Sci Technol 72:1588-1594.

Rhim, J.W.; Hong, S.I.; Ha. C.S. 2009. Tensile, water vapor barrier and antimicrobial properties of PLA/nanoclay composite films. LWT-Food Sci Technol 42:612-617.

Roohani, M.; Habibi, Y.; Belgacem, N.M.; Ebrahim, G.; Karimi, A.N.; Dufresne, A. 2008. Cellulose whiskers reinforced polyvinyl alcohol copolymers nanocomposites. Eur Polym J 44(8):24892498.

Sakurada, I.; Nukushina, Y.; Ito, T. 1962. Experimental determination of elastic modulus of crystalline regions in oriented polymers. J Polym Sci 57(165):651-60.

Visakh, P.M.; Thomas, S.; Oksman, K.; Mathew, A.P. 2012. Effect of cellulose nanofibers isolated from bamboo pulp residue on vulcanized natural rubber. Bioresources 7(2):2156-2168.

Vroman, I.; Tighzert, L. 2009. Review: Biodegradable Polymers. Mater 2:307-344. 